\title{
Longitudinal investigation of natural killer cells and cytokines in chronic fatigue syndrome/myalgic encephalomyelitis
}

Ekua W Brenu ${ }^{1,2^{*}}$, Mieke L van Driel ${ }^{1,2,4}$, Donald R Staines ${ }^{1,5}$, Kevin J Ashton ${ }^{2}$, Sharni L Hardcastle ${ }^{1,2}$, James Keane ${ }^{2}$, Lotti Tajouri ${ }^{2}$, Daniel Peterson ${ }^{6}$, Sandra B Ramos ${ }^{2}$ and Sonya M Marshall-Gradisnik ${ }^{1,2,3}$

\begin{abstract}
Background: Chronic Fatigue Syndrome/Myalgic Encephalomyelitis (CFS/ME) is an etiologically unexplained disorder characterised by irregularities in various aspects of the immunological function. Presently, it is unknown whether these immunological changes remain consistent over time. This study investigates Natural Killer (NK) cell cytotoxic activity, NK cell subsets $\left(\mathrm{CD} 56^{\text {bright }} \mathrm{CD} 16^{-}\right.$and $\left.\mathrm{CD} 56^{\mathrm{dim}} \mathrm{CD} 16^{+}\right)$and cytokines, over the course of a12 month period in patients with CFS/ME.

Methods: The participants in the study comprised 65 (47.2 \pm 11.5 years) CFS/ME participants and 21 (45.2 \pm 9.3 years) non-fatigued controls. Flow cytometry protocols were used to assess NK subsets and NK cytotoxic activity at various time points that included baseline (T1), 6 (T2) and 12 months (T3). Cytokine secretions were measured following mitogenic stimulation of peripheral blood mononuclear cells.
\end{abstract}

Results: NK cytotoxic activity was significantly decreased in the CFS/ME patients at T1, T2 and T3 compared to the non-fatigued group. Additionally, in comparison to the non-fatigued controls, the CFS/ME group had significantly lower numbers of CD56 $6^{\text {bright }} \mathrm{CD} 16^{-} \mathrm{NK}$ cells at both $\mathrm{T} 1$ and T2. Interestingly, following mitogenic stimulation, cytokine secretion revealed significant increases in IL-10, IFN- $\gamma$ and TNF- $a$ at T1 in the CFS/ME group. A significant decrease was observed at T2 in the CFS/ME group for IL-10 and IL-17A while at T3, IL-2 was increased in the CFS/ME group in comparison to the non-fatigued controls. Overall cytotoxic activity was significantly decreased at T3 compared to T1 and T2. CD56 ${ }^{\text {bright }} \mathrm{CD} 16^{-}$NK cells were much lower at T2 compared to T1 and T3. IL-10 and IL-17A secretion was elevated at $\mathrm{T} 2$ in comparison to $\mathrm{T} 1$ and $\mathrm{T} 3$.

Conclusion: These results confirm decreases in immune function in CFS/ME patients, suggesting an increased susceptibility to viral and other infections. Furthermore, NK cytotoxic activity may be a suitable biomarker for diagnosing CFS/ME as it was consistently decreased during the course of the 12 months study.

Keywords: Chronic fatigue syndrome, Cytokines, Cytotoxic activity

\footnotetext{
* Correspondence: ekbrenu@bond.edu.au

${ }^{1}$ Faculty of Health Science and Medicine, Population Health and

Neuroimmunology Unit, Bond University, Robina, QLD, Australia

${ }^{2}$ Faculty of Health Science and Medicine, Bond University, Robina, QLD 4229,

Australia

Full list of author information is available at the end of the article
} 


\section{Introduction}

Immune responses to infection and inflammation are important aspects of physiological homeostasis. This involves constant co-ordinated responses from and between the innate and adaptive immune systems $[1,2]$. Cells of the innate immune system in particular Natural Killer (NK) cells are important mediators of targeted cell killing of tumor, transformed and virus infected cells [3]. NK cells are recruited by interferons and chemoattractive chemokines including CCL22, CX3CL1 and CXCL8 [4-7]. At sites of infection, stochastic expression of NK receptors with the release of granzymes and perforin via mitogenic pathways ensures efficient elimination of unwanted cells [8-11].

As a disease with unknown pathomechanism and lacking specific diagnostic markers, Chronic Fatigue Syndrome/Myalgic Encephalomyelitis (CFS/ME) has been associated with diminished immune function [12]. CFS/ME is characterised by severe fatigue with apparent flu-like symptoms that either fluctuate or deteriorate and persist for many months to years $[13,14]$. To date cytokines, lymphocyte subsets and cytotoxic activity, have been examined in patients with CFS/ME using serum, plasma or blood samples. The findings from these investigations demonstrate equivocal quantities in lymphocyte numbers and cytokines but interestingly consistent decrease in NK cytotoxic activity [15-20].

A decrease in NK cytotoxic activity is thus a recurring finding in CFS/ME research [16,17,20-24] and remains a hallmark of the disease. Additionally, equivocal changes in NK cell subsets, $\mathrm{CD} 56^{\mathrm{dim}} \mathrm{CD} 16^{+}$ and $\mathrm{CD} 56^{\text {bright }} \mathrm{CD} 16^{-} \mathrm{NK}$ cells have been shown to occur $[20,25]$. Abnormalities in cellular levels of either CD56 ${ }^{\text {dim }}{ }^{2}$ D $16{ }^{+}$NK or $\mathrm{CD} 566^{\text {bright }} \mathrm{CD} 16^{-}$NK cells can affect cytokine production and subsequent clearance of pathogens. Despite these striking alterations there are no follow up studies reporting on the profiling of both NK cells subsets and activity during an extended course of CFS/ME. Perturbations in cytokine production favouring either an anti-inflammatory or proinflammatory cytokine profile may be prevalent in some CFS/ME patients [26-28]. CFS/ME is a chronic disease with a relatively long duration, persisting for more than 6 months, however, it is not reported yet whether alterations in cytokines occur and persist over time in adults with CFS/ME.

At this stage the diagnosis of CFS/ME is based on selfreported clinical symptoms. The difficulty in establishing a stringent medical diagnosis for CFS/ME may be related to the lack of data monitoring the stability of immune markers during the course of the disease. Almost all studies to date investigating immune function in CFS/ ME including cell activity, lymphocyte subsets and cytokines in CFS/ME adults were only restricted to single time point examination, providing insufficient information on the changes in these makers as the disease progresses. Additionally, there are many factors that can affect the differences in data reported. As CFS/ME is heterogeneous and multi-factorial, CFS/ME patients may experience periods of high, medium or low severity in symptoms which may be related to the levels of cytokines and immune function.

Therefore, the purpose of this study is to examine the validity and stability of immune parameters previously known to be compromised in CFS/ME and to determine most importantly whether these observations are consistent during the course of the disease. Assessment and evaluation of these markers potentially enables both the determination and knowledge of their stability over the course of the disease. This is the first longitudinal study assessing NK cytotoxic activity, NK subsets and $\mathrm{CD} 4^{+} \mathrm{T}$ cell cytokine distribution over a period of 12 months in adults suffering from CFS/ME.

\section{Methods}

\section{Recruitment}

Participants for this study were comprised of CFS/ME patients and non-fatigued controls recruited from an existing cohort in Queensland and New South Wales, Australia [25]. Prior to inclusion all participants completed a consent form and a questionnaire. The description of these participants is provided in Table 1. The CFS/ME group met the 1994 CDC criteria for CFS/ME and the control group consisted of nonfatigued volunteers. The non-fatigued controls were recruited from similar locations as the CFS/ME cohort. In both groups, individuals with known autoimmune

Table 1 Baseline clinical characteristics of chronic fatigue syndrome patients (cases) and non-fatigued controls

\begin{tabular}{lcc}
\hline & Cases (n=65) & Controls $(\mathbf{n}=\mathbf{2 1})$ \\
\hline Age, mean in years (SD) & $47.2(11.5)$ & $45.2(9.3)$ \\
Female (\%) & 75.4 & 66.7 \\
BMl kg/m² (SD) & $24.4(4.9)$ & $25.3(5.5)$ \\
Smoked in the past 2 years (\%) & 4.7 & 4.8 \\
Symptom (\%) & & \\
Weakness $>24$ hours after exercise & 93.8 & 9.5 \\
Unrefreshing sleep & 93.8 & 19.0 \\
Impaired concentration & 90.8 & 4.8 \\
Muscle pain & 81.5 & 14.3 \\
Joint pain & 70.8 & 9.5 \\
Headaches & 67.7 & 9.5 \\
Lymph glands & 43.1 & 0 \\
Sore throat & 46.2 & 8.0 \\
Diagnosed with depression or anxiety & 64.6 & 19.0 \\
\hline
\end{tabular}


disorders, psychosis, epilepsy, diabetes and cardiac related disorders prior to the onset of CFS/ME like symptoms were excluded from the study. These exclusions were also applied to the control group.

\section{Data collection}

Samples were collected at baseline (T1), after 6 months (T2) and after 12 months (T3). Blood collections were performed at three testing sites as it was not always feasible for participants to travel to the main testing site. Participants were recruited in 2009 and enlisted for the study in December 2009. The first collection was performed in December 2009. The second sampling point took place in June 2010 and the third in December 2010. Clinical data were collected through selfadministered questionnaires at (T1) and T3.

\section{Sample preparation and routine measurements}

Non-fasting morning blood samples were collected from the antecubital vein of all participants into lithium heparin $(12 \mathrm{~mL})$ and EDTA $(25 \mathrm{~mL})$ tubes. Regular full blood count (Coulter Counter, Beckman Coulter) assessments were performed ahead of immunological assessments. All analyses and experiments were performed immediately following blood collection. On a given day blood samples were collected from a maximum of 10 participants. These participants comprised of a mixture of CFS/ME patients and non-fatigued controls, however, as there were more CFS/ME patients compared to nonfatigued controls, in some cases the samples comprised only CFS/ME patients.

\section{NK cytotoxic activity}

NK cytotoxic activity was examined as previously described $[20,25,29]$. In brief, NK lymphocytes were isolated from blood samples using density gradient centrifugation and labelled with $0.4 \%$ PKH-26 (Sigma, St Louis, MO). Following which NK cells were incubated with $\mathrm{K} 562$ cells, for 4 hours at $37^{\circ} \mathrm{C}$ in $95 \%$ air, $5 \% \mathrm{CO}_{2}$ at an effector to target ratio of 25 (NK cells):1 (K562). An E:T ratio of 25:1 was chosen as we have previously found this ratio to be the most optimal condition for assessing cytotoxic activity. In previous studies this ratio has been used [20,25]. After four hours of incubation NK lysis of K562 cells was calculated as previously described [29] to determine the ability of NK cells to induce tumor cell death or apoptosis via FACS-Calibur flow cytometry (BD Bioscience, San Jose, CA), using Annexin V-FITC and 7-AAD reagents (BD Pharmingen, San Diego, CA). The NK assay was performed within 2-4 hours upon receipt of all blood samples for that particular day hence each sample was treated the same. Each sample was performed in duplicates and a control sample was included in each run.

\section{NK subsets}

The frequency of NK cell subsets was evaluated as previously described $[20,25]$. Briefly, a negative selection system using RosetteSep Human Natural Killer Cell Enrichment Cocktail (StemCell Technologies, Vancouver, BC) was used to segregate NK lymphocytes from whole blood. Preferentially isolated NK cells were then labelled with CD56-FITC and CD16-PE monoclonal antibodies (BD Pharmingen, San Jose, CA). In a forward scatter and side scatter plot created using the FACS-Calibur flow cytometry, a lymphocyte gate was set on NK cells. Subset profile was measured in a PE versus FITC plot.

\section{T cell specific cytokine distribution}

Isolated PBMCs were cultured at $1 \times 10^{6}$ cells $/ \mathrm{mL}$ with or without $1 \mu \mathrm{g}$ of phytohemagluttinin for 72 hours. Cellular supernatants were collected following incubation and stored at $-80^{\circ} \mathrm{C}$ for later assessment. Th1, Th2 and Th17 cytokine concentrations were determined using the cytometric bead array (CBA) kit (BD Pharmingen, San Jose, CA) $[25,30]$. The cytokines that were measured include IL-2, IL-4, IL-6, IL-10, tumour necrosis factor (TNF) $-\alpha$, interferon (INF) $-\gamma$ and IL-17A. The CBA kit includes a standard that is diluted at different concentrations as per manufacturer's instructions to produce a standard curve for each cytokine to be measured. This was included in the cytokine assessment. During each run of the CBA analysis control samples were included and each set of samples analysed on a given day consisted of both CFS/ME patients and non-fatigued control cell supernatants.

\section{Statistical analysis}

Statistical analysis was performed using SPSS software version 18.0. The experimental data represented in this study are reported as means plus/minus standard error of the mean $( \pm$ SEM) while all the clinical date are reported as means plus/minus standard deviation $( \pm S D)$. Comparative assessments among participants (CFS/ME and non-fatigued controls) were performed with the analysis of variance test (ANOVA) and repeated measures. For the repeated measures assessment time was the within-subjects factor and group was the between subject factor. Instances where Mauchly's test indicated that the sphericity assumption was breached, the Huynh-Feldt correction was applied. The Bonferroni method was used as post-hoc analysis to assess changes in the data. Time effects and group effects on the variables measured were assessed using eta squared $\left(\eta^{2}\right)$, where $\eta^{2}$ is the ratio of the sum of squares of the variance to the sum of squares of the total variance $\left(\eta^{2}=S_{\text {variance }}\right.$ effect $\left./ S S_{\text {total }}\right)$. To determine within subject stability Pearson and Spearman's rank correlations were determined between the three time points. 
P-values less than or equal to 0.05 were considered statistically significant.

\section{Ethical clearance and participant selection}

Approval for this study was granted after review by the Bond University Human Research Ethics Committee (R0852A).

\section{Results}

\section{Participants}

Data for baseline, 6 months and 12 months were available for 86 participants (65 CFS/ME patients and
21 non-fatigued controls). The mean age for the CFS/ ME patients was $47.2 \pm 11.5$ years and $45.2 \pm 9.3$ years for the non-fatigued controls. $75.4 \%$ of CFS/ME patients and $66.7 \%$ of the non-fatigued controls were female and the mean BMI in both groups was $24.5 \pm 5.0$ for the CFS/ME patients and $24.5 \pm 4.3$ for the nonfatigued controls. The CFS/ME patients had been suffering from fatigue for a mean of $16.4 \pm 12.5$ years and their mean score on the Fatigue Severity Scale (FSS) was $55.5 \pm 9.1$ (the lowest possible score of the FSS was 7 and highest is 63) [31]. Only $19.4 \%$ of patients indicated that they were still able to carry out normal
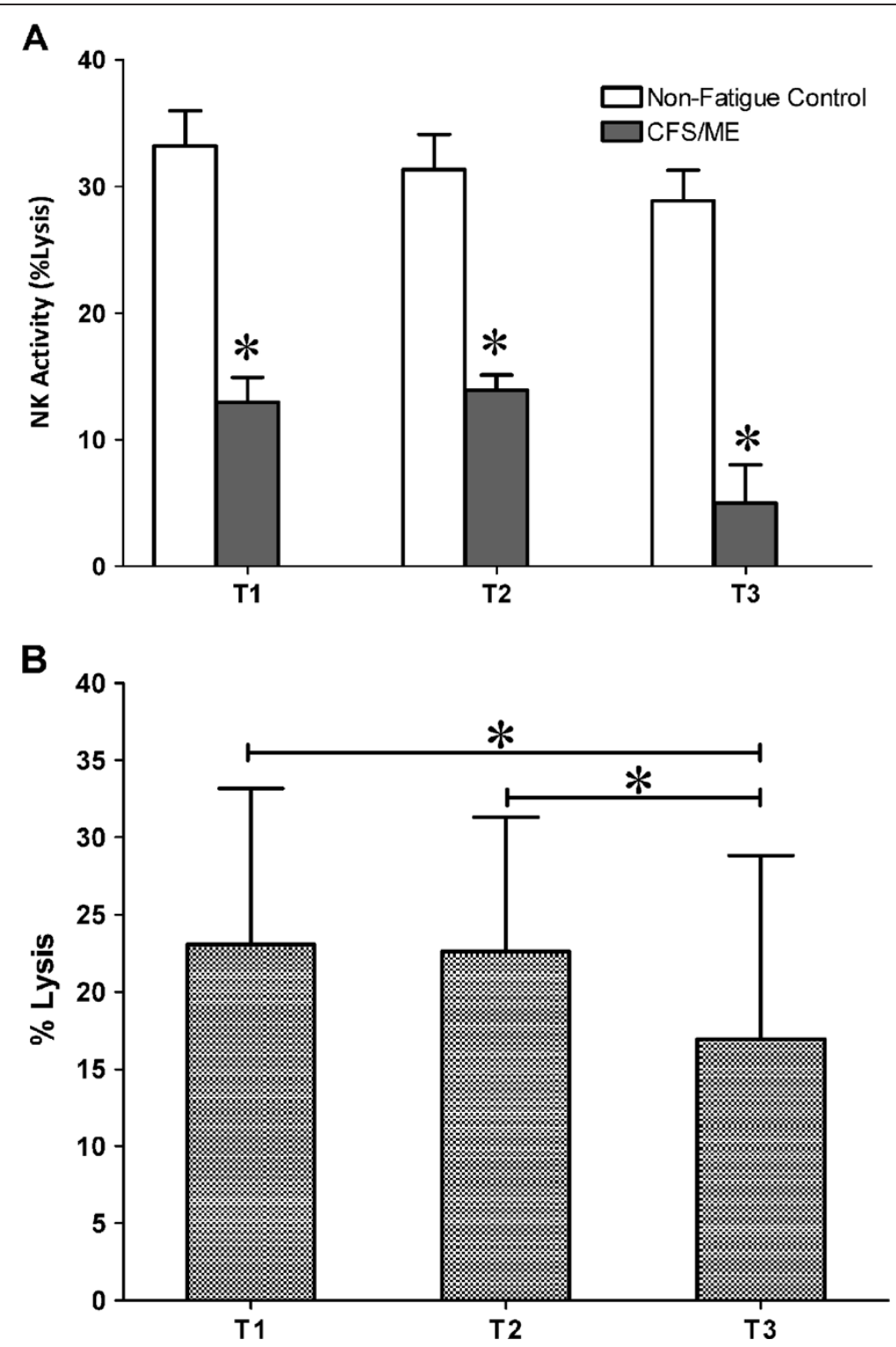

Figure 1 NK Cytotoxic activity was decreased at all time points in the CFS/ME patients. (A) Cytotoxic activity presented as \% lysis of K562 cells by NK cells assessed overtime at T1, T2 and T3 in the CFS/ME patients (black bars) and control (white bars) participants. (B) Cluster analysis showing the overall cytotoxic activity in the whole participant group. *Indicates statistical significant results relative to controls. Statistics are presented as mean \pm SEM. 
activities. Clinical baseline characteristics are reported in Table 1.

\section{Longitudinal assessment of NK cytotoxic activity}

NK cytotoxic activity, that is, the ability of the NK cells to effectively cause apoptosis of K562 cells was significantly reduced $(p<0.05)$ in $\mathrm{CFS} / \mathrm{ME}$ patients compared to the control group. Significant changes between the groups were noticed at the different time points, i.e. at T1 $(p<0.001)$, T2 $(p<0.001)$ and T3 $(p<0.001)$ (Figure 1A). Regardless of the time point cytotoxic activity remained significantly decreased $(p<0.001)$. Time effects
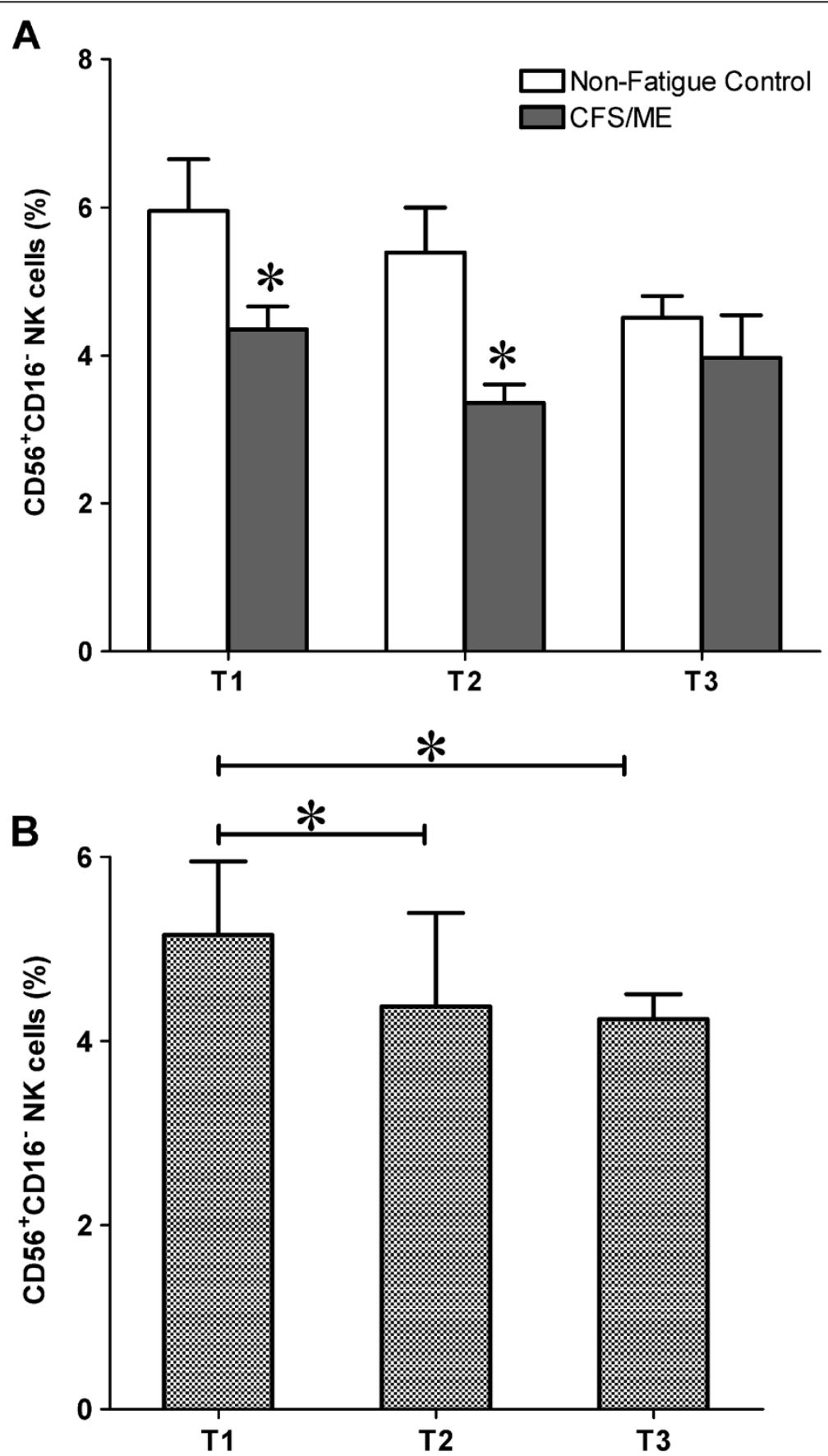

Figure $2 \mathrm{CD}^{6} 6^{\text {bright }} \mathrm{CD} 16^{-}$NK Subset was decreased in the CFS/ME group. Percentage of NK cells stained positive for CD56 ${ }^{\text {bright }} \mathrm{CD} 16^{-}$was significantly low in the CFS/ME group at the T1 and at T2. The white bars represent control data while the black bars represent CFS/ME data. (B) Cluster analysis showing the overall cytotoxic activity in the whole participant group. Data are presented in the form of log of the total events collected via flow cytometery \pm SEM. *Signifies statistical significant results relative to controls. 


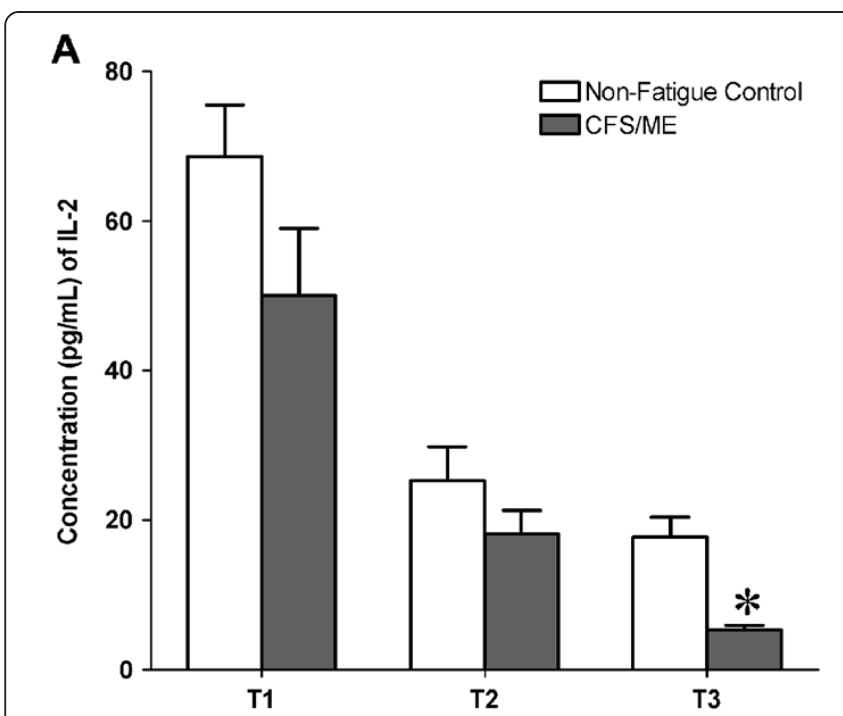

\section{B}

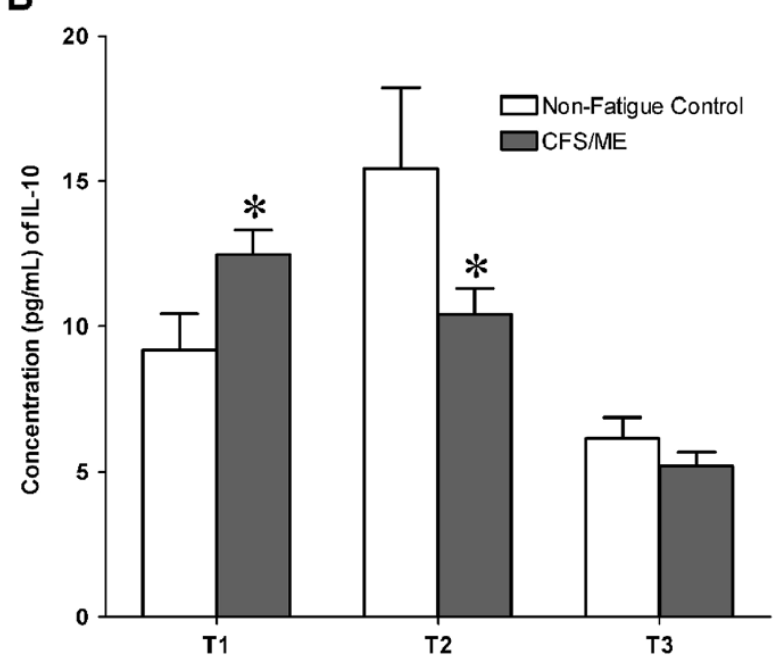

C
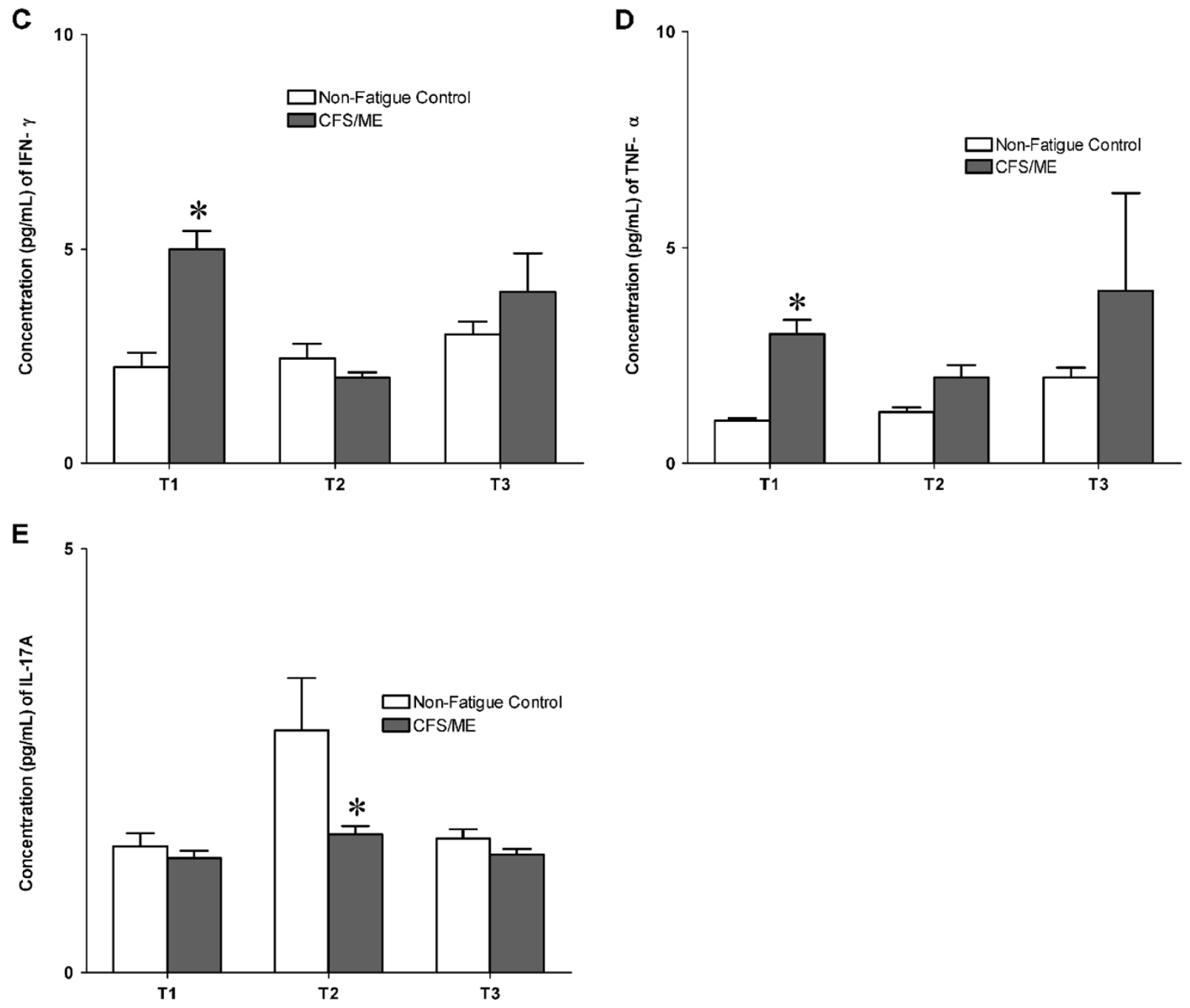

Figure $\mathbf{3}$ (See legend on next page.) 

patients at the T3, (B) IL-10 increased at the T1 and dropped significantly at the T2 in the CFS/ME group. (C) IL-17A was reduced at the T1 while (D) IFN- $\gamma$ and (E) TNF-a were increased significantly only at the T1. The CFS/ME data are signified by the black bars and non-fatigued controls the white bars. *Symbolizes statistically significant results were considered where $p \leq 0.05$. The results are expressed as the mean concentration at each time point \pm SEM

had no interaction with the group $(p=0.495)$. There were significant time effects cytotoxic activity from T1 to T3 $(p=0.023)$ and from T2 to T3 $(p=0.016)$ (Figure 1B).

\section{Differential distribution of NK cells between groups}

NK subsets were classified as $\mathrm{CD} 56{ }^{\mathrm{dim}} \mathrm{CD} 16^{+}$and CD56 ${ }^{\text {bright }} \mathrm{CD} 16^{-}$NK cells. $\mathrm{CD}^{-} 6^{\text {bright }} \mathrm{CD} 16^{-}$NK cells were significantly lower at T1 $(p=0.020)$ and T2 $(p<0.001)$ in CFS/ME patients compared to nonfatigued controls (Figure 2A). Significant time effects were observed for CD56 ${ }^{\text {bright }} \mathrm{CD} 16^{-} \mathrm{NK}$ cell $(p=0.003)$ in the overall group. Additionally, there was a significant interaction between time and group $(p=0.015)$. Pairwise comparison revealed significant changes in the overall group from the T1 to T2 $(p=0.037)$ and from T1 to T3 $(p=0.014)$ (Figure $2 \mathrm{~B})$. CD56 ${ }^{\mathrm{dim}} \mathrm{CD} 16^{+} \mathrm{NK}$ cells remained unchanged throughout the study for both groups.

\section{T cell related cytokine distribution}

Mitogenic stimulation produced significant differences in cytokine distribution observed at T1, T2 and T3. At T1, IL-10 $(p=0.051)$, IFN- $\gamma(p=0.003)$ and TNF- $\alpha$ $(p=0.002)$ were significantly increased in the CFS/ME patients compared to the non-fatigued controls (Figure 3B, D, E). IL-10 ( $p=0.026)$ and IL-17A $(p=0.002)$ were significantly decreased at T2 (Figure $3 \mathrm{~B}, \mathrm{C}$ ) and only IL-2 $(p=0.005)$ was significantly increased at T3 (Figure 3A). There was no significant difference in the remaining cytokines.

The production of some cytokines was significantly different from one time point to another. IL-2 was increased from T1 to T2 $(p<0.001)$ and from T1 to T3 $(p<0.001)$ (Figure 4A). IL-17A was increased from T1 to $\mathrm{T} 2(p=0.009)$ but declined from T2 to T3 $(\mathrm{p}=0.022)$ (Figure 4D). Secretion of IL-6 was decreased from T1 to T2 $(p=0.001)$ and T1 to T3 $(p=0.001)$ (Figure $4 \mathrm{~B})$. IL-10 progressively declined from T1 to T3 $(p<0.001)$ and T2 to T3 $(p<0.001)$ (Figure $4 \mathrm{C})$.

\section{Parameter stability}

In this study the stability of the immune parameters over time was assessed using Pearson and Spearman's correlation analysis, where significance was set at $P$ less than or equal to 0.05 . The results were highly significant for NK activity data (T1-T2; $p=0.003$, T1-T3; $p=0.032$ ).
Although, CD56 ${ }^{\text {bright }} \mathrm{CD} 16^{-} \mathrm{NK}$ cells were not significantly decreased at $\mathrm{T} 3$ the correlation between time points was significant (T1-T2; $p<0.0001$, T1-T3; $p<0.0001$, T2-T3; $p<0.0001)$. Of note, cytokines were not correlated at any time point. However decreases in IFN- $\gamma$, TNF- $\alpha$ and IL-10 were correlated at T1.

\section{Discussion}

Our investigation is the first study to demonstrate that NK cytotoxic activity remains consistently decreased in CFS/ME patients during the course of the disease. However, other immune parameters, especially cytokine secretions fluctuate at different time points and therefore demonstrate inconsistencies in their distribution pattern during the course of the disease. The purpose of this investigation was to identify immune markers that can be possibly used as biomarkers for CFS/ME in a longitudinal manner.

Primarily, this longitudinal study has illustrated that NK cytotoxic activity is potentially useful as a biomarker for CFS/ME, since it was the most stable in the CFS/ME patients over the 12 months period of the study. Decreases in cytotoxic activity occur in CFS/ME and in some cases this is associated with differential expression in the levels of cytotoxic molecules $[20,21,32,33]$. These cytotoxic proteins and their genes including perforin (PRF1), granzyme A (GZMA), granzyme B $(G Z M B)$ and granzyme $\mathrm{K}(G Z M K)$ have been shown to be either increased or decreased in CFS/ME [24,25,34]. For example, the perforin gene (PRF1) may increase in some cases of CFS/ME while intracellular perforin protein may be decreased in other CFS/ME patients [25]. Such profound differences in protein and mRNA can reduce the effectiveness of NK cells to induce lysis/cytotoxic activity of viral infected cells. Hence, defective cytotoxic activity in CFS/ME patients may be due to perturbations in the expression of cytotoxic factors resulting in reductions in cytotoxic proteins required for effective lysis of viral and microbial particles. Importantly, NK cells have both activating and inhibitory receptors, successful killing of target cells occurs through integrated signalling by activating and inhibitory receptors, and co-receptors. Inhibitory receptors are activated through the recognition of MHC class I proteins and this inhibits NK cytoxic activity [35,36]. Activating receptors are important for eliminating tumours, and other microbes through intracellular signal transduction mechanisms 


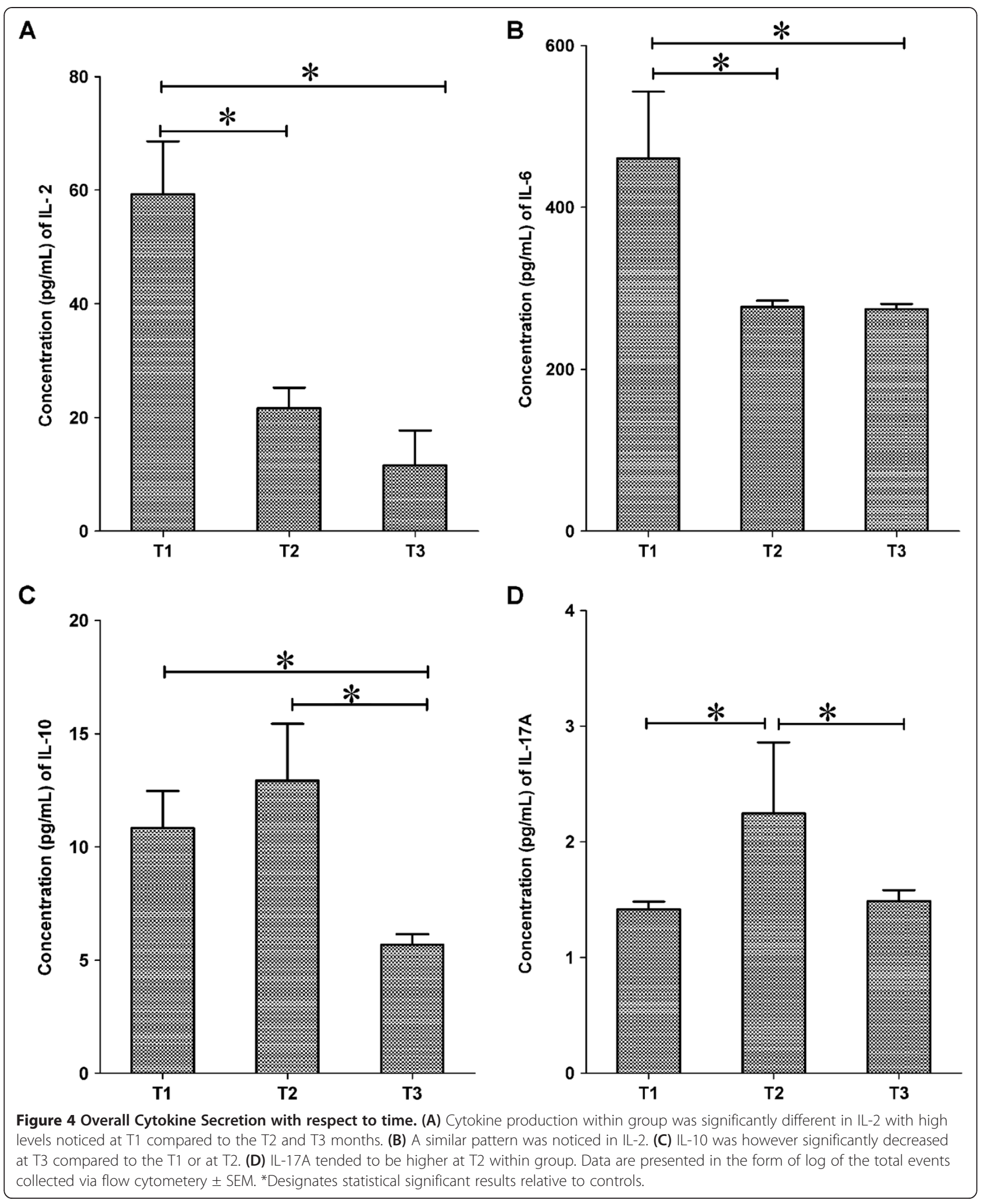


that connect them to immunodominant tyrosine based activation motif (ITAMS) adaptor proteins [35-37]. Certain viruses can affect NK receptor signalling thus reducing cytoxic activity. For example, the cytomegalovirus viral genes can regulate NK inhibitory receptor expression preventing the induction of activating receptors [38]. An increase in viral load occuring during the course of CFS/ME, may trigger defective cytotoxic receptor activations hence resulting in compromises to NK cytotoxic activity. The significance of the overall decrease in cytotoxic activity at $\mathrm{T} 3$ is unclear.

The exact consequence of alterations in $\mathrm{CD} 5^{\text {6bright }} \mathrm{CD} 16^{-}$ NK cells in CFS/ME is not fully known, however, patterns of $\mathrm{CD} 56^{\text {bright }} \mathrm{CD} 16^{-} \mathrm{NK}$ cells were affected by seasonal changes which may affect NK cytokine production. Incidentally gene expression of IFNG which is an important NK cytokine was significantly decreased in the NK cells of CFS/ME patients [25], which may be related to the decrease in CD56 ${ }^{\text {bright }} \mathrm{CD} 16^{-} \mathrm{NK}$ cells. Decreases in $\mathrm{CD}_{5} 6^{\text {bright }} \mathrm{CD} 16^{-} \mathrm{NK}$ cells have been observed in coronary heart disease, allergic rhinitis and juvenile rheumatoid arthritis while in diseases such as Chronic Obstructive Pulmonary Disease (COPD) CD $56^{\text {bright }} \mathrm{CD} 16^{-}$ NK cells have been reported to be increased $[39,40]$.

IL-2, a pro-inflammatory cytokine produced by Th1 cells [41] is required for naïve $\mathrm{CD} 4^{+} \mathrm{T}$ cell differentiation into Th2 and regulatory $\mathrm{T}$ cells (Tregs) in the presence of IL-4 and transforming growth factor beta (TGF- $\beta$ ) respectively [41]. Binding of IL-2 to its high affinity receptor IL-2R induces the proliferation of $\mathrm{T}$ cells and memory $\mathrm{CD}^{+}$and $\mathrm{CD} 8^{+} \mathrm{T}$ cells [42-44]. It is also has important roles in generating effector functions for $\mathrm{B}$ cells, CD56 ${ }^{\text {bright }} \mathrm{NK}$ and $\mathrm{CD} 8^{+} \mathrm{T}$ cells [45]. IL-2 regulates Treg cells and interestingly, $\mathrm{CD} 4{ }^{+} \mathrm{CD} 25^{+} \mathrm{Foxp} 3^{+}$Treg cells, have been reported to be significantly increased in the CFS/ME patients in comparison to non-fatigued controls [25]. An increase in IL-2 may suggest a shift towards Th1/pro-inflammatory immune response in CFS/ME patients.

Anti-inflammatory IL-10 exerts inhibitory effects on cytokine secretion and impedes pro-inflammatory cytokine secretion by multiple cells including Th1 cells (IFN- $\gamma$ ), macrophages/monocytes (IL-1, IL-T2, IL-8, IL-12 and TNF-) and NK cells (IFN- $\gamma$ and TNF- $\alpha$ ) [46]. A decrease in IL-10 favours an increase in proinflammatory responses and this may increase the prevalence of Th1 like cytokines. IL-17A is expressed by Th17 cells, it recruits and activates neutrophils, stimulates the generation of pro-inflammatory cytokines, chemokines and increases antimicrobial gene expression [47-50]. IL-17A is therefore an important immunoregulator during microbial infections as it activates immune cells to secrete pro-inflammatory factors. A decrease in IL-17A may contribute to the prevalence of infections.
A possible explanation for the observed changes in the secretion of this cytokine may be related to TGF- $\beta$ which at optimal levels directly promotes IL-17A generation while reducing IL-2 [51]. Thus, in the CFS/ME patients, TGF- $\beta$ may be decreased causing an increase in IL-2. Therefore, cytokine release in CFS/ME patients undergoes shifts during the course of the disease where patients may present with either an amplified or depressed anti-inflammatory or pro-inflammatory cytokine profile. These alterations in cytokine secretion may occur during the course of the disease and at different times causing either a shift towards a predominant Th1 or Th2 immune response in CFS/ME [25-27,52,53]. This makes it difficult to establish a unique CFS/ME-like inflammatory cytokine profile. The observed pattern of cytokine distribution among our CFS/ME patients is consistent with equivocal findings in the literature [54-58]. In adolescents with CFS/ME cytokine secretions have been observed to be correlated with seasonal variations [59]. Therefore, CFS/ME may be associated with oscillations in pro and anti-inflammatory cytokines, supporting the heterogeneity and multifactorial nature of the disease and the diversity in symptom presentations.

\section{Conclusion}

In conclusion, altered regulation of immunological function, in particular reduced cytotoxic activity of innate immune cells, is a key component of CFS/ME. This longitudinal study has identified NK cytotoxic activity and possibly $\mathrm{CD} 56^{\text {bright }} \mathrm{CD} 16^{-} \mathrm{NK}$ cells as potential biomarkers for diagnosing CFS/ME. The observation of immune dysregulation made in this study in relation to CFS/ME patients have been observed in various immunological diseases. This suggests the need for further investigations into the underlining disrupted mechanism of decreases in cytotoxic activity. It is important to note that these cytokine profiles were measured following mitogenic stimulation of PMBCs, serum measurements of cytokines may display different results. Further studies are therefore required to investigate whether changes in cytokine secretions from activated PMBCs and/or serum levels are associated with severity and progression of the complex clinical presentations in CFS/ME pathology.

\section{Competing interests}

The authors have no competing interests.

\section{Authors' contributions}

EWB DRS KJA MVD SMG designed the experiments. EWB SBR JK SLH executed the experiments. EWB performed all data analysis. SMG KJA supplied the reagents. MVD collected and analysed the clinical data. EWB wrote the paper. MVD KJA SMG DRS DP LT critically reviewed the manuscript. All authors read and approved the final manuscript.

\section{Acknowledgements}

This study was funded by the Queensland Smart State Government, Alison Hunter Memorial Foundation and the Mason Foundation. 


\section{Author details}

${ }^{1}$ Faculty of Health Science and Medicine, Population Health and Neuroimmunology Unit, Bond University, Robina, QLD, Australia. ${ }^{2}$ Faculty of Health Science and Medicine, Bond University, Robina, QLD 4229, Australia. ${ }^{3}$ School of Medical Science, Griffith Health Institute, Griffith University, Gold Coast Campus, Gold Coast, QLD, Australia. ${ }^{4}$ Discipline of General Practice, School of Medicine, The University of Queensland, Brisbane, Australia. ${ }^{5}$ Queensland Health, Gold Coast Public Health Unit, Robina, Gold Coast, QLD, Australia. ${ }^{6}$ Sierra Internal Medicine, Incline Village, Nevada, USA.

Received: 20 November 2011 Accepted: 15 March 2012 Published: 9 May 2012

\section{References}

1. Wasowska BA: Cross-talk between innate and adaptive immune responses in infection, transplant and autoimmune models. Curr Opin Organ Transplant 2011, 16:1-6.

2. Clark R, Kupper T: Old meets new: the interaction between innate and adaptive immunity. J Invest Dermatol 2005, 125:629-637.

3. Marcenaro E, Carlomagno S, Pesce S, Moretta A, Sivori S: Bridging innate NK cell functions with adaptive immunity. Adv Exp Med Biol 2011, 780:45-55.

4. Gong JH, Clark-Lewis I: Antagonists of monocyte chemoattractant protein 1 identified by modification of functionally critical $\mathrm{NH}$-terminal residues. J Exp Med 1995, 181:631-640.

5. Loetscher P, Seitz M, Clark-Lewis I, Baggiolini M, Moser B: Activation of NK cells by CC chemokines. Chemotaxis, Ca2+ mobilization, and enzyme release. J Immunol 1996, 156:322-327.

6. Bochner BS, Bickel CA, Taylor ML, MacGlashan DW Jr, Gray PW, Raport CJ Godiska R: Macrophage-derived chemokine induces human eosinophi chemotaxis in a CC chemokine receptor 3- and CC chemokine receptor 4-independent manner. J Allergy Clin Immunol 1999, 103:527-532.

7. Imai T, Chantry D, Raport CJ, Wood CL, Nishimura M, Godiska R, Yoshie O, Gray PW: Macrophage-derived chemokine is a functional ligand for the CC chemokine receptor 4. J Biol Chem 1998, 273:1764-1768.

8. Delgado DC, Hank JA, Kolesar J, Lorentzen D, Gan J, Seo S, Kim K, Shusterman S, Gillies SD, Reisfeld RA, et al: Genotypes of NK cell KIR receptors, their ligands, and Fcgamma receptors in the response of neuroblastoma patients to Hu14.18-IL2 immunotherapy. Cancer Res 2010, 70:9554-9561.

9. Marcenaro E, Carlomagno S, Pesce S, Chiesa MD, Parolini S, Moretta A Sivori S: NK cells and their receptors during viral infections. Immunotherapy 2011, 3:1075-1086.

10. Marras F, Bozzano F, De Maria A: Involvement of activating NK cell receptors and their modulation in pathogen immunity. J Biomed Biotechnol 2011, 2011:152430.

11. Vivier E, Nunes JA, Vely F: Natural killer cell signaling pathways. Science 2004, 306:1517-1519.

12. Lorusso L, Mikhaylova SV, Capelli E, Ferrari D, Ngonga GK, Ricevuti G: Immunological aspects of chronic fatigue syndrome. Autoimmun Rev 2009, 8:287-291.

13. Fukuda K, Straus SE, Hickie I, Sharpe MC, Dobbins JG, Komaroff A: The chronic fatigue syndrome: a comprehensive approach to its definition and study. International Chronic Fatigue Syndrome Study Group. Ann Intern Med 1994, 121:953-959.

14. Wallman KE, Morton AR, Goodman C, Grove R: Reliability of physiological, psychological, and cognitive variables in chronic fatigue syndrome. Res Sports Med 2005, 13:231-241.

15. Tirelli U, Marotta G, Improta S, Pinto A: Immunological abnormalities in patients with chronic fatigue syndrome. Scand J Immunol 1994, 40:601-608

16. Barker E, Fujimura SF, Fadem MB, Landay AL, Levy JA: Immunologic abnormalities associated with chronic fatigue syndrome. Clin Infect Dis 1994, 18(Suppl 1):S136-S141.

17. Masuda A, Nozoe SI, Matsuyama T, Tanaka H: Psychobehavioral and immunological characteristics of adult people with chronic fatigue and patients with chronic fatigue syndrome. Psychosom Med 1994, 56:512-518.

18. Racciatti D, Dalessandro M, Delle-Donne L, Falasca K, Zingariello P, Paganelli $R$, Pizzigallo $E$, Vecchiet J: Study of immune alterations in patients with chronic fatigue syndrome with different etiologies. Int J Immunopathol Pharmacol 2004, 17:57-62.
19. Stewart CC, Cookfair DL, Hovey KM, Wende KE, Bell DS, Warner CL: Predictive immunophenotypes: disease-related profile in chronic fatigue syndrome. Cytometry B Clin Cytom 2003, 53:26-33

20. Brenu EW, Staines DR, Baskurt OK, Ashton KJ, Ramos SB, Christy RM, Marshall-Gradisnik SM: Immune and hemorheological changes in chronic fatigue syndrome. J Trans/ Med 2010, 8:1.

21. Klimas NG, Salvato FR, Morgan R, Fletcher MA: Immunologic abnormalities in chronic fatigue syndrome. J Clin Microbiol 1990, 28:1403-1410.

22. Fletcher MA, Zeng XR, Maher K, Levis S, Hurwitz B, Antoni M, Broderick G, Klimas NG: Biomarkers in chronic fatigue syndrome: evaluation of natural killer cell function and dipeptidyl peptidase IV/CD26. PLoS One 2010, 5:e10817.

23. Ojo-Amaize EA, Conley EJ, Peter JB: Decreased natural killer cell activity is associated with severity of chronic fatigue immune dysfunction syndrome. Clin Infect Dis 1994, 18(Suppl 1):S157-S159.

24. Maher KJ, Klimas NG, Fletcher MA: Chronic fatigue syndrome is associated with diminished intracellular perforin. Clin Exp Immunol 2005, 142:505-511.

25. Brenu EW, van Driel ML, Staines DR, Ashton KJ, Ramos SB, Keane J, Klimas NG, Marshall-Gradisnik SM: Immunological abnormalities as potential biomarkers in Chronic Fatigue Syndrome/Myalgic Encephalomyelitis. J Transl Med 2011, 9:81.

26. Skowera A, Cleare A, Blair D, Bevis L, Wessely SC, Peakman M: High levels of type 2 cytokine-producing cells in chronic fatigue syndrome. Clin Exp Immunol 2004, 135:294-302.

27. Swanink CM, Vercoulen JH, Galama JM, Roos MT, Meyaard L, van der VenJongekrijg J, de Nijs R, Bleijenberg G, Fennis JF, Miedema F, van der Meer JW: Lymphocyte subsets, apoptosis, and cytokines in patients with chronic fatigue syndrome. J Infect Dis 1996, 173:460-463.

28. Metzger K, Fremont M, Roelant C, De Meirleir K: Lower frequency of IL-17 F sequence variant (His161Arg) in chronic fatigue syndrome patients. Biochem Biophys Res Commun 2008, 376:231-233.

29. Aubry JP, Blaecke A, Lecoanet-Henchoz S, Jeannin P, Herbault N, Caron G, Moine V, Bonnefoy JY: Annexin V used for measuring apoptosis in the early events of cellular cytotoxicity. Cytometry 1999, 37:197-204.

30. Dickson L, Finlayson K: VPAC and PAC receptors: from ligands to function. Pharmacol Ther 2009, 121:294-316.

31. Krupp LB, LaRocca NG, Muir-Nash J, Steinberg AD: The fatigue severity scale. Application to patients with multiple sclerosis and systemic lupus erythematosus. Arch Neurol 1989, 46:1121-1123.

32. Klimas NG, Koneru AO: Chronic fatigue syndrome: inflammation, immune function, and neuroendocrine interactions. Curr Rheumatol Rep 2007, 9:482-487.

33. Robertson MJ, Schacterle RS, Mackin GA, Wilson SN, Bloomingdale KL, Ritz J, Komaroff AL: Lymphocyte subset differences in patients with chronic fatigue syndrome, multiple sclerosis and major depression. Clin Exp Immunol 2005, 141:326-332.

34. Saiki T, Kawai T, Morita K, Ohta M, Saito T, Rokutan K, Ban N: Identification of marker genes for differential diagnosis of chronic fatigue syndrome. Mol Med 2008, 14:599-607.

35. Biassoni R: Human natural killer receptors, co-receptors, and their ligands. Curr Protoc Immunol 2009, Chapter 14:Unit 1410.

36. Biassoni R, Cantoni C, Pende D, Sivori S, Parolini S, Vitale M, Bottino C, Moretta A: Human natural killer cell receptors and co-receptors. Immunol Rev 2001, 181:203-214

37. Moretta A, Bottino C, Vitale M, Pende D, Cantoni C, Mingari MC, Biassoni $\mathrm{R}$, Moretta L: Activating receptors and coreceptors involved in human natural killer cell-mediated cytolysis. Annu Rev Immunol 2001 19:197-223.

38. Reyburn HT, Mandelboim O, Vales-Gomez M, Davis DM, Pazmany L, Strominger JL: The class I MHC homologue of human cytomegalovirus inhibits attack by natural killer cells. Nature 1997, 386:514-517.

39. Scordamaglia F, Balsamo M, Scordamaglia A, Moretta A, Mingari MC, Canonica GW, Moretta L, Vitale M: Perturbations of natural killer cell regulatory functions in respiratory allergic diseases. J Allergy Clin Immunol 2008, 121:479-485.

40. Hak L, Mysliwska J, Wieckiewicz J, Szyndler K, Trzonkowski P, Siebert J, Mysliwski A: NK cell compartment in patients with coronary heart disease. Immun Ageing 2007, 4:3.

41. Zhu J, Paul WE: CD4 T cells: fates, functions, and faults. Blood 2008, 112:1557-1569. 
42. Thornton AM, Donovan EE, Piccirillo CA, Shevach EM: Cutting edge: IL-2 is critically required for the in vitro activation of $\mathrm{CD} 4+\mathrm{CD} 25+\mathrm{T}$ cell suppressor function. J Immunol 2004, 172:6519-6523.

43. Williams MA, Tyznik AJ, Bevan MJ: Interleukin-2 signals during priming are required for secondary expansion of CD8+ memory T cells. Nature 2006, 441:890-893.

44. Yamane H, Zhu J, Paul WE: Independent roles for IL-2 and GATA-3 in stimulating naive CD4+ T cells to generate a Th2-inducing cytokine environment. J Exp Med 2005, 202:793-804.

45. Fehniger TA, Cooper MA, Nuovo GJ, Cella M, Facchetti F, Colonna M, Caligiuri MA: CD56bright natural killer cells are present in human lymph nodes and are activated by T cell-derived IL-2: a potential new link between adaptive and innate immunity. Blood 2003, 101:3052-3057.

46. Commins SP, Borish L, Steinke JW: Immunologic messenger molecules: cytokines, interferons, and chemokines. J Allergy Clin Immunol 2010, 125 : S53-S72.

47. Weaver $C T$, Hatton RD, Mangan PR, Harrington LE: IL-17 family cytokines and the expanding diversity of effector T cell lineages. Annu Rev Immunol 2007, 25:821-852.

48. Fossiez F, Djossou O, Chomarat P, Flores-Romo L, Ait-Yahia S, Maat C, Pin JJ, Garrone P, Garcia E, Saeland S, et al: T cell interleukin-17 induces stromal cells to produce proinflammatory and hematopoietic cytokines. J Exp Med 1996, 183:2593-2603.

49. Liang SC, Tan XY, Luxenberg DP, Karim R, Dunussi-Joannopoulos K, Collins M, Fouser LA: Interleukin (IL)-22 and IL-17 are coexpressed by Th17 cells and cooperatively enhance expression of antimicrobial peptides. J Exp Med 2006, 203:2271-2279.

50. Ouyang $\mathrm{W}$, Kolls JK, Zheng Y: The biological functions of $\mathrm{T}$ helper 17 cell effector cytokines in inflammation. Immunity 2008, 28:454-467.

51. Cejas PJ, Walsh MC, Pearce EL, Han D, Harms GM, Artis D, Turka LA, Choi Y: TRAF6 inhibits Th17 differentiation and TGF-beta-mediated suppression of IL-2. Blood 2010, 115:4750-4757.

52. Broderick G, Fuite J, Kreitz A, Vernon SD, Klimas N, Fletcher MA: A formal analysis of cytokine networks in Chronic Fatigue Syndrome. Brain Behav Immun 2010, In Press.

53. Fletcher MA, Zeng XR, Barnes Z, Levis S, Klimas NG: Plasma cytokines in women with chronic fatigue syndrome. J Transl Med 2009, 7:96.

54. Patarca R, Klimas NG, Lugtendorf S, Antoni M, Fletcher MA: Dysregulated expression of tumor necrosis factor in chronic fatigue syndrome: interrelations with cellular sources and patterns of soluble immune mediator expression. Clin Infect Dis 1994, 18(Suppl 1):S147-S153.

55. Linde A, Andersson B, Svenson SB, Ahrne H, Carlsson M, Forsberg P, Hugo $H$, Karstorp A, Lenkei $R$, Lindwall $A$, et al: Serum levels of lymphokines and soluble cellular receptors in primary Epstein-Barr virus infection and in patients with chronic fatigue syndrome. J Infect Dis 1992, 165:994-1000.

56. Lloyd A, Hickie I, Hickie C, Dwyer J, Wakefield D: Cell-mediated immunity in patients with chronic fatigue syndrome, healthy control subjects and patients with major depression. Clin Exp Immunol 1992, 87:76-79.

57. Peakman M, Deale A, Field R, Mahalingam M, Wessely S: Clinical improvement in chronic fatigue syndrome is not associated with lymphocyte subsets of function or activation. Clin Immunol Immunopathol 1997, 82:83-91.

58. Gold D, Bowden R, Sixbey J, Riggs R, Katon WJ, Ashley R, Obrigewitch RM, Corey $L$ : Chronic fatigue. A prospective clinical and virologic study. JAMA 1990, 264:48-53.

59. ter Wolbeek M, van Doornen LJ, Kavelaars A, van de Putte EM, Schedlowski $\mathrm{M}$, Heijnen $\mathrm{CJ}$ : Longitudinal analysis of pro- and anti-inflammatory cytokine production in severely fatigued adolescents. Brain Behav Immun 2007, 21:1063-1074

doi:10.1186/1479-5876-10-88

Cite this article as: Brenu et al:: Longitudinal investigation of natural killer cells and cytokines in chronic fatigue

syndrome/myalgic encephalomyelitis. Journal of Translational Medicine 2012 10:88.

\section{Submit your next manuscript to BioMed Central and take full advantage of:}

- Convenient online submission

- Thorough peer review

- No space constraints or color figure charges

- Immediate publication on acceptance

- Inclusion in PubMed, CAS, Scopus and Google Scholar

- Research which is freely available for redistribution

Submit your manuscript at www.biomedcentral.com/submit
C Biomed Central 